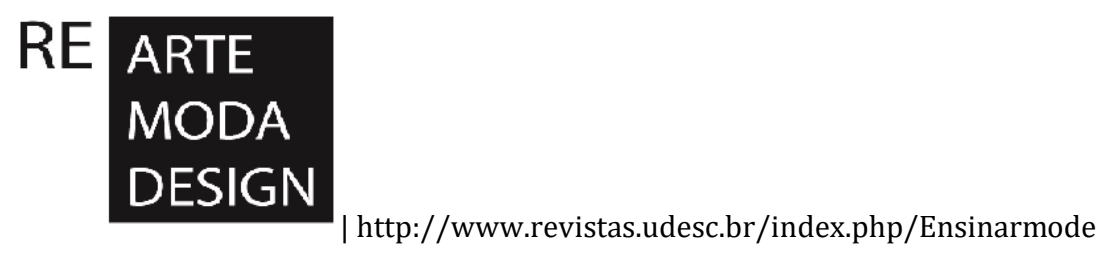

\title{
DOCÊNCIA E PLANEJAMENTO DE CURSOS PARA AS ÁREAS DA ECONOMIA CRIATIVA
}

Teaching and course planning for the areas of the creative economy

Heloisa Helena de Oliveira Santos ${ }^{1}$

\section{RESUMO}

O artigo tem como objetivo discutir a atuação docente na formulação de cursos em instituições públicas de ensino. Para discutir esta atuação, a metodologia proposta é a de formulação de um curso cujas etapas envolvem o diagnóstico e análise do histórico, características e necessidades/demandas do local em que o curso se insere, incluindo o acompanhamento do público que atualmente frequenta a instituição de ensino, alinhamento com a proposta institucional e proposta de curso que se fundamente nestas informações levantadas. Também apresentamos, no artigo, os resultados do planejamento de um curso livre que tem como referência as noções de economia criativa e que busca atender a demanda específica de formação de mulheres, população mais vulnerável socialmente, em uma região empobrecida localizada na Baixada Fluminense/Rio de Janeiro.

Palavras chave: Docência. Planejamento de cursos. Economia criativa. Geração de renda.

\begin{abstract}
The article aims to discuss teacher's work in the planning of courses in public teaching institutions. To discuss this kind of activity, the proposed methodology is the creation of a course which steps consist in the analysis of the history, characteristics and needs / demands of the place in which the institution is inserted, including the monitoring of the necessities and desires of our current students, alignment with the institutional proposal and the course proposal itself based on those information. The article also presents the planning results of this proposal in which we used the notions of creative economy as a fundamental reference and in which we seek to meet the specific demand for qualifying of women, the population more vulnerable socially, in an impoverished region located at Baixada Fluminense / Rio de Janeiro.
\end{abstract}

Keywords: Teaching. Classes planning. Creative economy. Income generating.

\footnotetext{
1 Professora do Ensino Básico, Técnico e Tecnológico no Instituto Federal do Rio de Janeiro. É docente na área de Produção de Vestuário, lecionando disciplinas na área de modelagem, costura e tingimento. É bacharel e licenciada em Ciências Sociais e Mestre em Sociologia e Antropologia, ambas pela UFRJ. Também é Tecnóloga em Produção de Vestuário pelo SENAI CETIQT e Doutora em Design pela PUC-Rio.

E-mail: heloisa.oliveira@ifri.edu.br | Lattes: http://lattes.cnpq.br/2359181214524364

Revista ENSINARMODE, Florianópolis, Vol. 2, N. 1, Fevereiro-Maio 2018, p. 149-172. DOI: http://dx.doi.org/10.5965/25944630212018149 | ISSN 2594-4630
} 


\section{RE ARTE \\ MODA \\ DESIGN \\ | http://www.revistas.udesc.br/index.php/Ensinarmode}

\section{INTRODUÇÃO}

O trabalho do professor nas escolas é geralmente centrado no planejamento das aulas e em sua atuação nos ambientes de aprendizagem, mediando os processos de ensino-aprendizagem. Contudo, o professor, em parceria com a equipe pedagógica da instituição ao qual está vinculado, é um ator fundamental para a idealização, projeto, planejamento e construção de cursos: uma vez que está em contato direto com os discentes, o docente pode ser um canal central de comunicação entre as demandas dos alunos e as equipes dirigentes e pedagógicas, trazendo para estas últimas as informações que recebe diretamente e que podem se tornar possíveis ofertas de cursos livres ou disciplinas não obrigatórias da instituição e, especialmente, participando na proposição e formulação de cursos.

Infelizmente, este é um tipo de atuação docente pouco discutido e explorado. De um lado porque o planejamento de cursos fica muitas vezes centralizado em apenas uma pessoa que, nem sempre, é professor. De outro porque este tipo de atividade é poucas vezes trazida como uma possibilidade de atuação nos cursos de licenciatura e formação docente. Contudo, o professor pode não apenas encontrar em sua carreira a oportunidade de formular cursos, mas também materiais didáticos e outros produtos pedagógicos. Quando lembramos, contudo que, no Brasil, a licenciatura não é uma obrigatoriedade para o ensino em grande parte das áreas das ciências humanas e sociais aplicadas, podemos compreender a pouca discussão sobre o papel e atuação docente na criação e desenvolvimento do conteúdo de materiais educacionais nestas áreas. A autora teve a oportunidade de se licenciar durante sua primeira formação e destaca a importância da mesma para o desenvolvimento e prática profissional docente, especialmente para os professores provenientes do mercado ou recém-formados em áreas técnicas e/ou aplicadas.

O tema central deste artigo é a atuação do professor de moda em instituições públicas de ensino como mediador dos processos de qualificação socioprofissional e geração de renda, centralmente entre a população de baixa renda, por meio da formulação dos cursos cuja preocupação central seja a de não apenas formar mão de obra barata para o mercado. A motivação central da pesquisa é a atuação da docente 


\section{RE ARTE \\ MODA \\ DESIGN \\ | http://www.revistas.udesc.br/index.php/Ensinarmode}

em um novo espaço profissional, a cidade de Belford Roxo, munícipio localizado no Grande Rio, ou seja, nos arredores da capital do estado do Rio de Janeiro.

O objetivo do artigo é discutir a atuação docente na formulação de cursos em instituições públicas de ensino. Para discutir esta atuação, a metodologia proposta é a de diagnóstico e análise do histórico, características e necessidades/demandas do local em que o curso se insere, incluindo acompanhamento do público que frequenta a instituição de ensino; alinhamento com a proposta institucional; e proposta de curso que se oriente para as informações levantadas. Apresentamos, no artigo, os resultados do planejamento de um curso livre que tem como referência as noções de economia criativa e que busca atender a demanda específica de formação de mulheres, população mais vulnerável socialmente, em uma região empobrecida localizada na Baixada Fluminense/Rio de Janeiro. Assim, neste texto não teremos como foco a apresentação dos dados levantados.

Como apontado, entre os fundamentos para esta proposta de qualificação e geração de renda, estão os conceitos acerca da Economia Criativa, ferramentas que, quando utilizadas sob a ótica da promoção social e da redução da desigualdade, podem ser instrumentos reais de modificação do status quo. $O$ texto apresenta os primeiros resultados da pesquisa e trabalho iniciados em 2017 juntamente com o grupo de pesquisa em fase de cadastramento no CNPq intitulado "Setores Criativos: ensino, pesquisa e práticas pedagógicas".

Este artigo vai se organizar da seguinte maneira: na primeira seção, apresentaremos a proposta de atuação social que fundamenta a criação dos Institutos Federais de Educação (IF), órgão ao qual a autora está atualmente vinculada. Os IFs orientam sua ação educacional no sentido de modificar a realidade do local onde o mesmo se encontra, valorizando o potencial local. A proposta de formulação do curso aqui apresentada busca, neste sentido, se alinhar à proposta institucional, daí a importância de apresentar a mesma.

$\mathrm{Na}$ segunda seção, apresentaremos a cidade de Belford Roxo, espaço de atuação da docente e do instituto. O município, localizado na Baixada Fluminense, apresenta um dos índices de desenvolvimento humano (IDH) mais críticos do estado, estando na $71^{\circ}$ entre os 92 municípios que compõem atualmente o Rio de Janeiro, 


\section{RE ARTE \\ MODA \\ DESIGN}

segundo os dados desenvolvidos pelo PNUD (2013) com referência no censo de 2010. $\mathrm{Na}$ terceira parte, abordaremos alguns conceitos de Economia Criativa. Esta última, em sua relação com o design e a moda no país, foi tema da tese de doutoramento da autora, defendida em 2015. As noções aqui apresentadas serão centralmente aquelas discutidas na tese.

$\mathrm{Na}$ última sessão, apresentaremos o projeto propriamente dito. Uma síntese da proposta de trabalho será apresentada por meio do plano de curso e matriz, a fim de que possamos discutir a proposta de atuação do docente de moda junto à população de baixa renda em regiões empobrecidas pelo Estado. É fundamental destacar desde já que a utilização da expressão "regiões empobrecidas pelo Estado" não é apenas ocasional, mas política: a ideia que se deseja afirmar é a de que a pobreza não é uma essência do ser ou local, mas uma ação do Estado na figura de seus governantes que, por ausência de vontade política, produzem e reproduzem as desigualdades sociais por meio das quais alimentam a si e aos seus. Esperamos, com este trabalho, poder dialogar com os pares sobre esta proposta de atuação e discutir sua construção e viabilidade.

\section{INSTITUTOS FEDERAIS, EDUCAÇÃO E ATUAÇÃO LOCAL}

A atuação docente na formulação de cursos e matérias pedagógicos demanda não apenas uma vontade pessoal, mas também um espaço de trabalho que o estimule e incentive sua atuação nestas áreas, seja concedendo-lhe horas de planejamento, seja envolvendo-o em projetos institucionais que o qualifiquem e 0 participem nestas atividades. A autora teve a oportunidade de atuar na formulação de cursos e desenvolvimento de materiais didático-pedagógicos em duas instituições privadas nas quais atuou: SENAC Rio e SENAI CETIQT. Em ambas, houve a proposição da atividade, assim como capacitação e remuneração para o desenvolvimento destas atividades.

Contudo, encontramos diversos docentes hoje que, por meio das mídias digitais, desenvolvem vídeos e materiais em texto e slides e o divulgam de forma gratuita nas redes. Este trabalho revela o potencial docente para o desenvolvimento 


\section{RE ARTE \\ MODA \\ DESIGN}

destes materiais, assim como a necessidade crescente de se discutir a pedagogia aplicada às novas mídias.

Os Institutos Federais de Educação (IF) constituem a rede federal de educação brasileira e são espaços de educação reconhecidos como de elevada qualidade. Os professores são incentivados a se qualificar e remunerados por esta qualificação, considerando-se aí a qualificação do professor como uma qualificação do processo de ensino-aprendizagem de modo mais amplo. É relevante entender o contexto de criação dos mesmos.

Após sete anos de embate, em 2004 inicia-se a reorientação das políticas federais para a educação profissional e tecnológica, primeiro com a retomada da possibilidade da oferta de cursos técnicos integrados com o ensino médio seguida, em 2005, da alteração na lei que vedava a expansão da rede federal. (SILVA, 2009, p. 7/8)

Os Institutos Federais de Educação (IF) podem ser considerados uma das principais resultantes das mudanças politico-institucionais no âmbito da educação promovidas pelo governo Lula. Um marco do descaso no Era FHC, momento em que foi vedada a expansão da rede federal de educação profissional no país que foi relegada aos Estados e à rede privada² , a educação profissional em nível médio torna-se, ainda durante a primeira gestão, um dos focos principais de atuação do governo federal.

A Lei que regulamento os institutos federais não apenas apontava a criação de dezenas de escolas de nível técnico e tecnológico que ofertam ensino médio integrado e subsequente, como também associa as unidades já existentes - inclusive a rede CEFET, os colégios de aplicação (CAP) vinculados às universidades federais e o Colégio Pedro II -, alterando a perspectiva tradicional de abandono político das obras realizadas por governos anteriores. Considerado parte da política de nação empreendida pelo governo, os IFs são percebidos como instrumentos de desenvolvimento de país e ferramenta desta política. Os institutos podem oferecer educação profissional em todos os níveis e modalidades da educação profissional, atuando, contudo, de maneira compromissada com o desenvolvimento integral do cidadão trabalhador.

Em síntese, esse novo desenho constituído traz como principal função a intervenção na realidade, na perspectiva de um país soberano e inclusivo,

\footnotetext{
${ }^{2}$ Além de retirar a responsabilidade da esfera federal, a gestão FHC dificultou a oferta do ensino médio geral integrado ao ensino técnico, o que favorecia as entidades privadas de ensino que ofertam cursos técnicos concomitantes e subsequentes. 


\section{RE ARTE \\ MODA \\ DESIGN}

| http://www.revistas.udesc.br/index.php/Ensinarmode

tendo como núcleo para irradiação das ações o desenvolvimento local e regional. O papel que está previsto para os Institutos Federais é o de garantir a perenidade das ações que visem a incorporar, antes de tudo, setores sociais que historicamente foram alijados dos processos de desenvolvimento e modernização do Brasil, o que legitima e justifica a importância de sua natureza pública e afirma uma educação profissional e tecnológica como instrumento realmente vigoroso na construção e resgate da cidadania e da transformação social. (PACHECO, s/a., p. 14)

A região em que se insere um IF é de fundamental importância para a própria organização da instituição. Tal fato ocorre porque a proposta dos mesmos envolve uma atuação cujo foco esteja na melhoria do lugar em que o mesmo se encontra instalado, de modo que o IF se torne um local de referência para os habitantes. A educação, desta maneira, entra como um agente de modificação regional, devendo, por esta razão, ser instalado não nos grandes centros urbanos/capitais, mas preferencialmente em localidades mais distantes destes centros, onde o ensino público e de qualidade é escasso e onde a desigualdade socioeducacional seja uma evidente desenvolvedora da própria desigualdade econômica. A proposta envolve, ainda, uma preocupação em investigar os potenciais locais, de maneira a não impor qualificações que não estejam de acordo com a realidade do lugar, mas formações coerentes com o mercado de trabalho dos arredores.

O território de abrangência das ações de um Instituto é, em resumo, a mesorregião onde se localiza, mas pode ir além dela quando se concebe sua atuação em rede. Em sua intervenção, os Institutos devem explorar as potencialidades de desenvolvimento, a vocação produtiva de seu lócus; a geração e transferência de tecnologias e conhecimentos e a inserção, nesse espaço, da mão de obra qualificada. Para tanto, o monitoramento permanente do perfil socioeconômico-político-cultural de sua região de abrangência é de suma importância. (PACHECO, s/a, p. 15/6)

Assim, observa-se uma percepção de instituição educacional como parte e instrumento de uma política pública orientada por uma perspectiva de nação inclusiva e democrática, que atua modificando o local em que se instala por meio da qualificação profissional dos moradores de uma região, aproveitando, sempre que possível, os potenciais locais. A educação, neste sentido, se torna a mediadora de um processo maior de redução das desigualdades sociais. Desta maneira, desenvolver cursos que atendam às demandas da população local, no caso dos institutos federais, se alinha com a própria proposta desta instituição. 


\section{RE ARTE \\ MODA \\ DESIGN}

| http://www.revistas.udesc.br/index.php/Ensinarmode

Como o lugar em que se instala o instituto é fundamental para a proposta político pedagógica e seleção dos cursos a serem oferecidos, vamos apresentar, na próxima seção, alguns dados e características do município de Belford Roxo.

\section{BELFORD ROXO: "SOCIOLOCALIZAÇÃO"}

O planejamento docente envolve não apenas adequar o conteúdo para os diferentes níveis de ensino, mas refletir sobre a melhor metodologia a ser aplicada, alinhando-a com as metodologias institucionais e, principalmente, considerar quem é o aluno e o lugar no qual ele está atuando. Este último aspecto é de fundamental importância: conhecer a história e características do lugar, bairros e municípios limítrofes, principais atividades comerciais, instituições e dados demográficos ajudam o docente a contextualizar suas aulas e torna-las mais próximas dos alunos e de sua realidade.

Belford Roxo é, historicamente falando, um município jovem. Antes distrito de Nova Iguaçu, cidade também localizada na região da Baixada Fluminense, Belford Roxo apenas se constituiu como município autônomo em 1990 (IBGE, 2016). Com cerca de 470 mil habitantes, de acordo com o Censo de 2010, a cidade é essencialmente urbana. Belford Roxo dista cerca de $30 \mathrm{~km}$ do centro da capital, de carro e a linha férrea que conecta a Central do Brasil até Belford Roxo faz o percurso em cerca de uma hora.

Figura 1: Localização de Belford Roxo tendo a capital do Estado como referência.

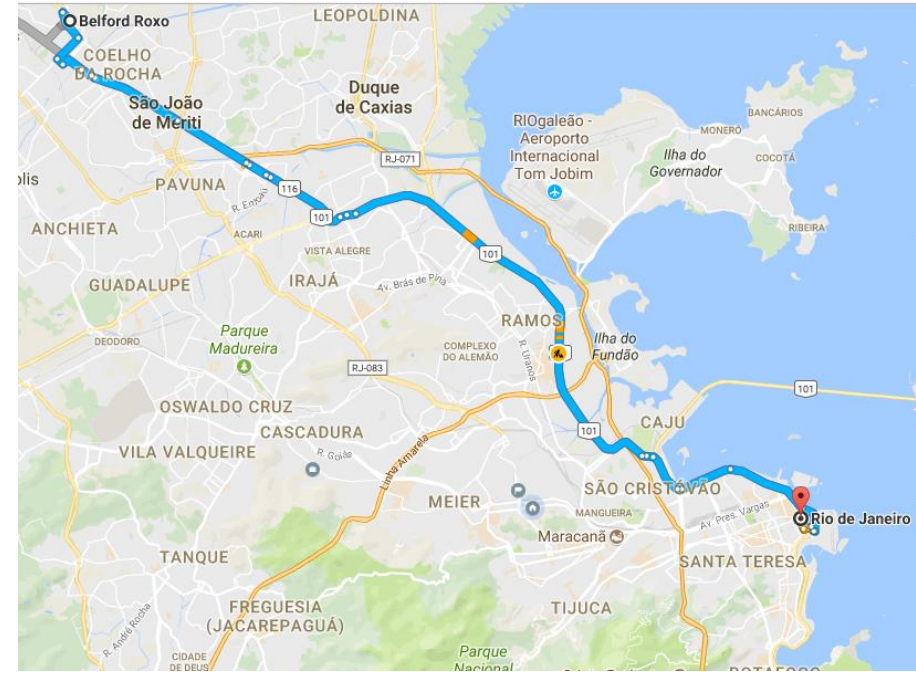

Fonte: Google Maps. 


\title{
RE ARTE \\ MODA \\ DESIGN
}

A cidade faz divisa com Nova Iguaçu, Mesquita, Duque de Caxias e São João de Meriti, todos importantes municípios da região metropolitana do Rio de Janeiro. No último deles se localiza um grande polo de confecção e comercialização de jeans e roupas em geral, qual seja, Vilar dos Teles. Considerando a importância do potencial local para definição dos cursos do instituto, compreendemos a criação dos cursos na área de moda e, Belford Roxo.

Figura 2: Município de Belford Roxo com destaque para a localização do IF e de Vilar dos Teles.

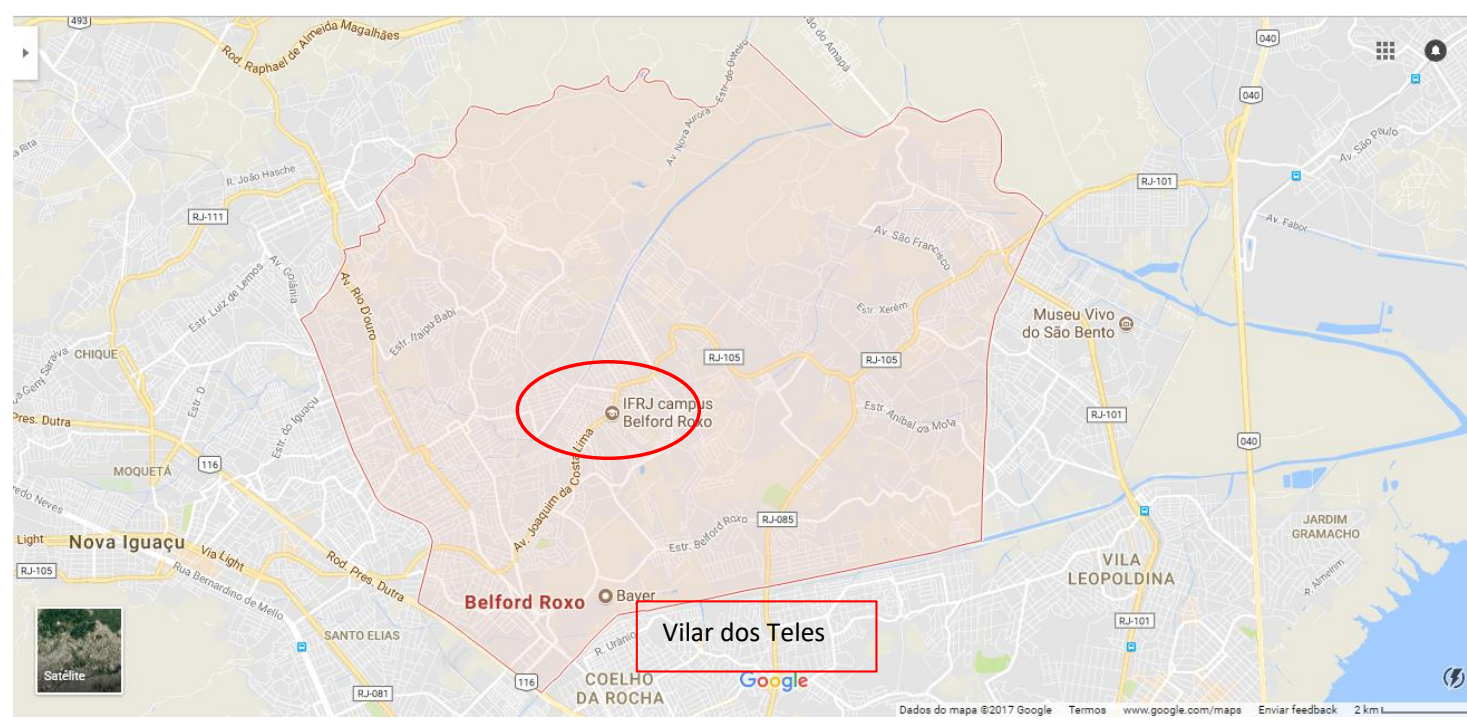

Fonte: Desenvolvido pela autora a partir de imagens do Google Maps.

Durante muito tempo, o bairro de Vilar dos Teles dominava a produção e comercialização de jeans na cidade. No entanto, vem atualmente dividindo espaço com outros centros, como aponta matéria do Jornal o Dia sobre o comércio de jeans no estado:

\begin{abstract}
A busca por preços mais baixos cresceu tanto que o comércio desse tipo de roupa, antes concentrado em Vilar dos Teles, em São João de Meriti, se expandiu para outros locais, como a Saara, no Centro do Rio, e os bairros Alcântara e Nova Cidade, ambos em São Gonçalo. (SOROSINI, $17 / 09 / 2015)$
\end{abstract}

Os dados sociais de Belford Roxo não são os mais animadores. Ainda segundo informações do Censo de 2010 do IBGE, um pouco mais de 6000 pessoas frequentavam o Ensino Superior na cidade e menos de 250 pessoas estavam cursando Mestrado ou Doutorado. A estes dados se agregam a triste informação de que cerca de 200 mil pessoas com mais de dez anos (total em torno de 440 mil) foram categorizadas como sem instrução ou não completaram o ensino fundamental. Os dados apontam 


\section{RE ARTE \\ MODA \\ DESIGN}

ainda um total de mais de 18 mil pessoas analfabetas com mais de 15 anos de idade, sendo a maioria mulheres (10.407 mulheres). São mulheres, ainda, que chefiam mais de 62 mil domicílios na cidade: a maior parte entre elas é preta ou parda. Vale destacar ainda que o rendimento médio de todas as fontes de mulheres acima de 10 anos em 2010 era de $R \$ 710,57$ (a dos homens era $R \$ 1016,20$ ). Causa ou consequência, mais de 11 mil domicílios tinham, à época, renda per capita de até 1/4 do salário mínimo: dentre estes, mais de 6 mil não tinham pavimentação no entorno e mais de 2.300 ainda conviviam com esgoto a céu aberto.

A localidade de Belford Roxo também já foi considerada uma das mais violentas do Estado. Segundo tabela desenvolvida pelo Laboratório de Análise de Violência da UERJ, em 2004, a cidade estava em 4º lugar no índice de homicídios. Os dados são referentes ao ano de 2001:

Figura 3: Tabela com registro de taxa de homicidio em cidades do Estado.

\begin{tabular}{|c|c|c|c|}
\hline \multicolumn{4}{|c|}{$\begin{array}{l}\text { Taxa de Homicídio por Município em } 2001 \\
\text { Região Metropolitana do Rio de Janeiro }\end{array}$} \\
\hline Municipio & $\begin{array}{l}\text { Número de } \\
\text { homicídios }\end{array}$ & $\begin{array}{l}\text { População } \\
\text { Residente }\end{array}$ & $\begin{array}{c}\text { Taxa por } \\
100.000 \\
\text { hab. }\end{array}$ \\
\hline Belford Roxo & 328 & 444.820 & 73,73 \\
\hline Duque de Caxias & 527 & 789.981 & 66,67 \\
\hline Guapimirim & 18 & 39.016 & 46,86 \\
\hline Itaboraí & 131 & 193.702 & 67,57 \\
\hline Itaguaí & 51 & 85.034 & 59,95 \\
\hline Japeri & 61 & 85.261 & 72,01 \\
\hline Magé & 114 & 296.828 & 38,41 \\
\hline Mangaratiba & 6 & 26.134 & 22,73 \\
\hline Marica & 32 & 80.794 & 39,21 \\
\hline Mesquita & 72 & 170.035 & 42,45 \\
\hline Nilópolis & 91 & 153.209 & 59,10 \\
\hline Niterói & 221 & 461.386 & 47,94 \\
\hline Nova Iguaçu & 580 & 772.487 & 75,12 \\
\hline Paracambi & 7 & 40.704 & 17,85 \\
\hline Queimados & 113 & 124.898 & 90,66 \\
\hline São Gonçalo & 516 & 904.903 & 57,04 \\
\hline São Joăo de Meriti & 370 & 452.935 & 81,61 \\
\hline Seropédica & 45 & 67.672 & 67,08 \\
\hline Tanguá & 13 & 26.922 & 46,44 \\
\hline Rio de Janeiro & 3268 & 5.930 .213 & 55,10 \\
\hline $\begin{array}{l}\text { Outros Municípios da } \\
\text { Região Metropolitana }\end{array}$ & 3296 & 5.216 .724 & 63,19 \\
\hline Região Metropolitana & 6564 & 11.146.936 & 58,89 \\
\hline
\end{tabular}

Fonte: Cano; Sento-Sé; Ribeiro, 2004.

Como pode ser visto na tabela, Belford Roxo foi ultrapassada apenas por municípios próximos/vizinhos, todos localizados também na Baixada Fluminense: Queimados, São João de Meriti e Nova Iguaçu. Historicamente, a Baixada, como é 


\section{RE ARTE \\ MODA \\ DESIGN}

frequentemente denominada a região pelos moradores da cidade, é conhecida por ainda ser um lócus de pobreza e violência.

Figura 4: Municípios da baixada Fluminense.

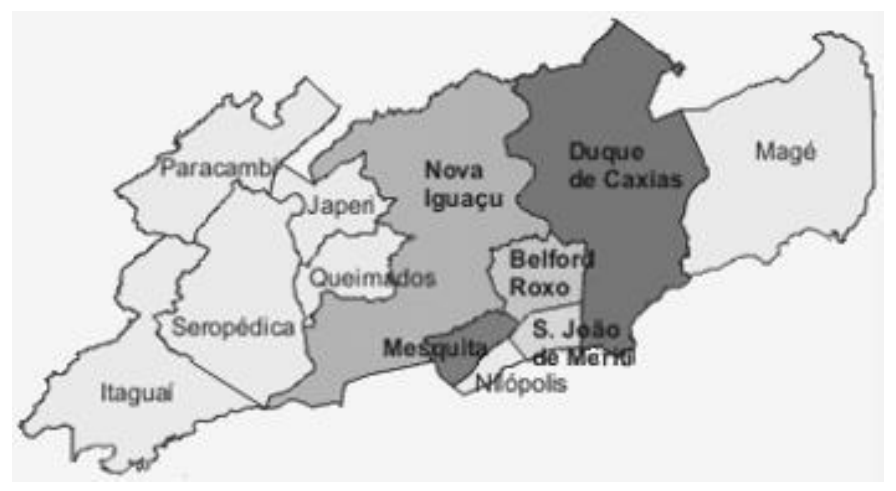

Fonte: Wikipedia.

Considerando a proposta político-pedagógica dos IF, é possível identificar, na cidade de Belford Roxo, uma série de elementos que justificam a instalação de um polo de educação de referência que possa qualificar as cidadãs e cidadãos do local e das redondezas. Vale destacar que também foram criados institutos federais em outras seis cidades da região da Baixada Fluminense. Neste sentido, a atuação politicamente atuante dos docentes pode ser de fundamental importância para a promoção da qualidade de vida dos mesmos.

\section{ECONOMIA CRIATIVA: BREVES CONSIDERAÇÕES}

A unidade de Belford Roxo está reunindo diversos cursos que atuam, direta ou indiretamente, com os setores da Economia Criativa. Muito já se discutiu sobre a economia criativa, mas as definições ainda são difusas. Trata-se, genericamente definindo, da troca e comércio de bens cuja base é a criatividade. Estes bens, em sua maioria, estão inseridos no comércio dos países, mas não costumam ser contabilizados como parte do mercado produtivo ou do PIB, especialmente porque seu valor se encontra não centralmente ou apenas em seu valor financeiro, mas fundamentalmente no valor intangível que o constituem. Como aponta Klamer (2016, p. 8): 


\section{RE ARTE \\ MODA \\ DESIGN}

| http://www.revistas.udesc.br/index.php/Ensinarmode

com máquinas e trabalho) constituem apenas uma fração dos preços; pessoas pagam majoritariamente pelas imagens que elas representam, pela marca, por seus significados. O valor adicionado é em sua maioria imaginário, ou seja, está na mente das pessoas. Para fazer justiça à economia criativa, nós precisamos quebrar com o confinamento do pensamento econômico tradicional.

O crescimento, ou melhor, a popularização da economia criativa está diretamente relacionada com as mudanças propostas pelo governo britânico no final dos anos 1990. Ainda que as primeiras reflexões tenham ocorrido na Austrália e o conceito de nação criativa tenha sido lá pela primeira vez mencionado, foram as discussões no Reino Unido que trouxeram ao centro do debate o tema da criatividade como insumo para as atividades produtivas. Tal processo ocorre já no final do século $X X$, após o processo de desindustrialização inglês, momento em que há uma redução generalizada de empregos no país. Com a crise financeira global de 2008, torna-se necessário pensar em alternativas para o reaquecimento da economia. É exatamente neste momento que surge a reflexão sobre a criatividade como insumo para o trabalho.

É quando as ditas "economias avançadas" se desindustrializam que "fazer dinheiro com ideias" torna-se plausível, senão necessário. É no momento em que se desmantela a "condição salarial" [...] que "já não podemos mais falar em empregados das $8 \mathrm{~h}$ às $18 \mathrm{~h}$ ", mas de empregos criativos e flexíveis. É quando o PIB cresce enquanto a renda das famílias e os empregos diminuem que se torna preciso pensar em outros tipos de trabalho. Não é à toa que os ventos da economia criativa sopram inicialmente da desindustrializada e financeirizada Londres. (MICHETTI, 2012b, p. 176)

A definição dos setores que comporiam a indústria criativa inglesa ficou sob a responsabilidade do Departamento de Cultura, Mídia e Esporte (DCMS) que encomendou uma pesquisa a fim de definir o setor. No entendimento do órgão, os setores criativos podem ser definidos como as áreas "que têm sua origem na criatividade, na perícia e no talento individuais e que possuem um potencial para a criação de riqueza e empregos através da geração e da exploração da propriedade intelectual" (DCMS apud FIRJAN, 2008, p. 7 - grifos nossos), o que revela grande ênfase às características individuais e aos rendimentos privados, como podemos perceber. A seleção incluía os setores de publicidade, arquitetura, mercado de artes e antiguidades, artesanato, design, moda, filmagem, softwares interativos de lazer, 


\title{
RE ARTE \\ MODA \\ DESIGN
}

| http://www.revistas.udesc.br/index.php/Ensinarmode

música, artes performáticas, editoração, serviços de computação e rádio \& televisão.

Esta abrangência, como indicado, foi costurada por meio da noção de criatividade:

Desde logo, o documento resultante [da discussão do DCMS] definia as indústrias criativas, em primeiro lugar, a partir da união de diversas atividades: culturais (pintura, música, dança, cinema etc.), de comunicação (imprensa, rádio, televisão), de desenho (desenho industrial, moda, diversas especialidades de design) e de tecnologias da informação (conteúdos para internet, jogos eletrônicos, produção de hardwares e softwares). A despeito da singularidade de cada uma dessas atividades, afirmava-se que todas comungavam de "criatividade", termo que era definido como sendo originado a partir da habilidade e talento individuais cujos produtos apresentavam potencial para geração de empregos e riquezas por meio da exploração de propriedade intelectual, outro aspecto que definia essas atividades. (DE MARCHI, 2014: 198 — grifos nossos)

Como é assinalado no documento da Federação das Indústrias do Rio de Janeiro - FIRJAN (2008, p. 7), as áreas consideradas parte do núcleo criativo pelo DCMS compreendiam centralmente "atividades de serviços e comércio", sendo que esta foi a primeira classificação realizada que incluiu áreas que, até aquele momento, não eram entendidas como primordialmente culturais, podendo ser mencionadas aqui centralmente a grande indústria, como é o caso do setor de design. Assim, percebemos que é nesse momento que se iniciou a construção de uma nova abordagem sobre a cultura que deixa de conter apenas as áreas tradicionais e passa a incluir atividades que delas são aproximadas. Contudo, estes setores não são apropriados sem uma avaliação de um "grau de cultura envolvido", aquilo que foi denominado pelo DCMS como "testes da cultura". Vale citar um trecho da publicação do DCMS citado em Reis (2012):

\begin{abstract}
As "indústrias criativas" são analiticamente primas-irmãs das indústrias culturais; diferentes mas obviamente da mesma família ou atividade. O que elas produzem tem alto grau de valor simbólico e funcional. Arquitetura, design, moda, serviços de computação e propaganda são tipicamente setores criativos, que no mercado têm de passar pelos testes da cultura e funcionalidade. Anúncios têm de vender produtos, mas funcionam melhor quando expressam firmemente a cultura. Edifícios devem ser tanto esteticamente agradáveis como funcionais. Design deve incorporar cultura, mas é inútil se os produtos não funcionam direito. Roupas devem ser culturalmente de vanguarda mas ao mesmo tempo trajáveis. Nem todo edifício roupa, anuncio ou peça de design passa por ambos os testes, mas as indústrias criativas são mais saudáveis e vitais quando o maior número possível deles passa. (DCMS a apud REIS, 2012, p. 43).
\end{abstract}

Tal definição foi tomada como referência por toda a reflexão posterior sobre as indústrias criativas, ainda que não tenha se tornado unânime. Sob o ponto de 


\section{RE ARTE \\ MODA \\ DESIGN}

vista da ênfase fornecida à criatividade na sua relação com o comércio, a economia criativa permite valorizar uma série de atividades produtivas que podem ser uma importante alternativa para a geração de trabalho e renda. Esta é a perspectiva central da ONU que, em 2008, lança um documento em que incentiva que os governos dos países em desenvolvimento invistam nestas áreas. Apesar das críticas, as noções de economia criativa são avaliadas, no relatório, por meio de uma visão bastante positiva cujo objetivo parece ser abrir uma nova possibilidade de atuação para as economias em desenvolvimento, possibilidade esta que teria a cultura e a criatividade - própria de qualquer atividade humana - a seu serviço. Nesta perspectiva, define-se as indústrias criativas:

[...] como os ciclos de criação, produção e distribuição de bens e serviços que usam a criatividade e o capital intelectual como principais insumos. Elas compreendem um conjunto de atividades baseadas no conhecimento que produzem bens tangíveis e intangíveis, intelectuais e artísticos, com conteúdo criativo e valor econômico. (UNCTAD, 2010, p. XVI)

Considerando este crescimento e a expansão em potencial da Economia Criativa, o relatório destaca em diversos momentos a importância dos governos criarem políticas públicas específicas para o setor. Para tal, devem avaliar as particularidades de suas economias, reconhecendo suas necessidades reais, alinhadas com suas diferenças culturais e identitárias, a fim de investir nos produtos com maior possibilidade de retorno: desta maneira, cada nação deve analisar onde está o seu potencial particular. Este posicionamento se alinha com uma perspectiva que não mais valida políticas internacionais de desenvolvimento baseadas em modelos generalistas que se vendem como salvacionistas, especialmente quando se conhece que as teorias econômicas tradicionais já se demonstraram incapazes de dar conta das assimetrias não apenas econômicas, mas também culturais das diversas sociedades. Ainda que direcionados para o setor criativo, estes investimentos não devem apenas se voltar para a esfera do econômico, uma vez que a natureza multidisciplinar da economia criativa demanda ações interministeriais. Deste modo, o relatório orienta que os governos desenvolvam políticas públicas para os setores cultural, tecnológico, ambiental, educacional e social de modo mais amplo, além de ações voltadas para o crescimento de uma economia que se desenvolva de maneira sustentável. Assim, se de um lado há um 


\section{RE ARTE \\ MODA \\ DESIGN}

incentivo para que os países em geral invistam na economia criativa como alternativa, de outro estimula-se a busca por soluções locais para este estímulo, baseando-se em áreas que se revelem lucrativas para cada caso em particular.

No Brasil, a discussão sobre a economia criativa ganha espaço no setor público com o lançamento do Plano da Secretaria de Economia Criativa. Em coerência com a mudança iniciada com a gestão de Juca Ferreira, no PSEC constrói-se uma nova percepção sobre o MinC, de modo que o órgão deixa de ser um ator secundário dentro do planejamento político de governo e passa a ser compreendido como um articulador de projetos interministeriais alinhados a outros planos de governo, como é o caso do "Brasil sem Miséria" e do "Brasil Maior" que são nominalmente mencionados. O objetivo, como é destacado, é inserir a cultura dentro da perspectiva do desenvolvimento, de modo a atender a premissa expressa na Constituição Federal que entende ser aquela um direito do cidadão. Neste sentido, a reflexão sobre o desenvolvimento passa a envolver, dentro de sua concepção, o entendimento de que a esfera do simbólico-cultural contribui para a sua produção. Como indica De Marchi (2012, p. 1), entendida a partir de uma perspectiva desenvolvimentista, a cultura, em decorrência, passa a ser percebida como um ativo econômico, de modo que as produções que possuem como principal valor seus aspectos simbólicos passam também a ser posicionadas em local privilegiado, segundo o autor. No caso brasileiro, a análise e desenvolvimento de uma política para a economia criativa fica a cargo do MinC. 


\section{RE ARTE \\ MODA \\ DESIGN}

| http://www.revistas.udesc.br/index.php/Ensinarmode

Figura 5: Escopo dos setores criativos segundo a Secretaria de Economia Criativa.

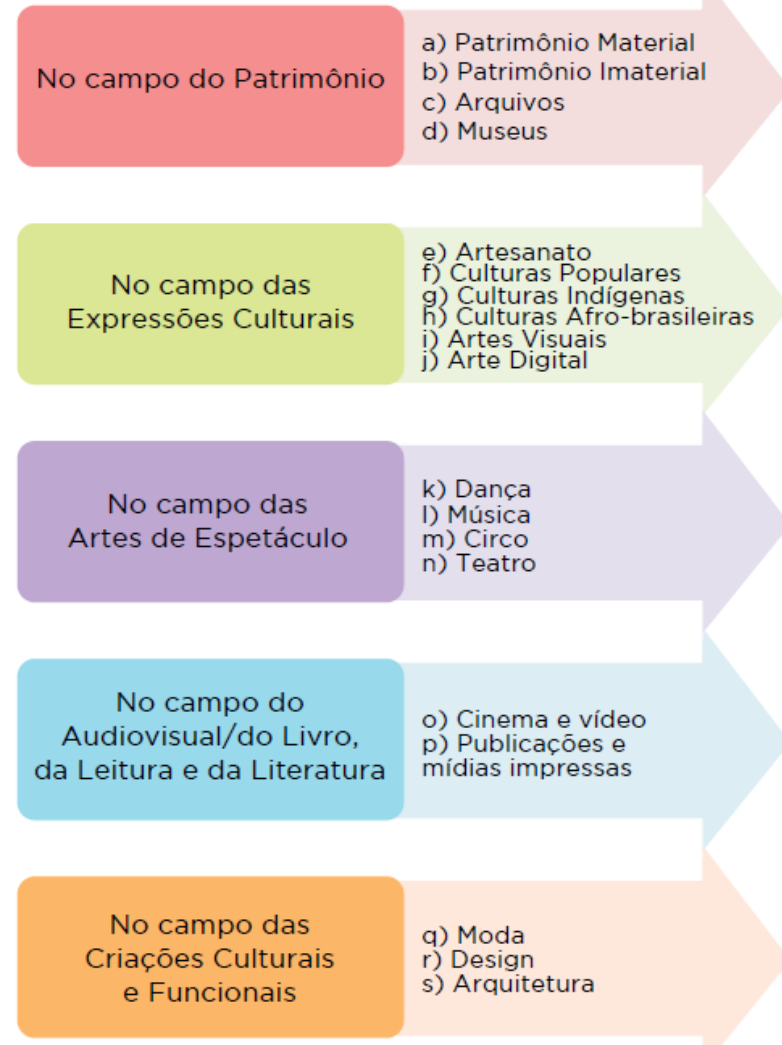

Fonte: MinC, 2012, p. 30.

O Ministério da Cultura se coloca o desafio de formular, implementar e monitorar as políticas públicas para um modelo de desenvolvimento cujas bases estão "na inclusão social, na sustentabilidade, na inovação e, especialmente, na diversidade cultural brasileira" (MINC, 2012, p. 7). Aproveitando as classificações realizadas pelas diversas instituições ao redor do mundo, mas se guiando pela sugestão da ONU de observar as especificidades e o potencial local, a Secretaria de Economia Criativa apresenta esta classificação para os setores criativos. A moda é uma das áreas inseridas na Economia Criativa no Brasil. Considerando esta inserção, o projeto docente desenvolvido visa a constituição da qualificação socioprofissional orientada para o desenvolvimento de negócios criativos cuja ênfase não esteja no individualismo dos empreendedorismos tradicionais, mas que se volte para a realização de parcerias entre os produtores envolvidos. Estas parcerias, além de beneficiar os negócios, também têm como objetivo promover a localidade, seja pelo aumento da oferta de empregos, seja pela oportunização de alternativas à violência e pobreza. 


\title{
RE ARTE \\ MODA \\ DESIGN
}

\section{DOCÊNCIA, FORMULAÇÃO DE CURSO E ATUAÇÃO SOCIAL NA GERAÇÃO DE RENDA}

O projeto foi desenvolvido no ano de 2017 com o objetivo de ser analisado e corrigido ainda neste ano e desenvolvido em 2018. Seu foco central está na qualificação na área de moda em diálogo com a economia criativa e o empreendedorismo, buscando ainda a formação integral dos alunos, isto é, uma qualificação que não se centre apenas no desenvolvimento de competências técnicas, mas também a formação humana, socioprofissional e política. Considera-se que o instituto possa se tornar um espaço ou comunidade criativa, um local de referência para que pessoas criativas possam aprender e trocar experiências, assim como adquirir conhecimentos para iniciar práticas e/ou aperfeiçoá-las. A presença desse lugar de referência é fundamental, pois nestes ambientes estimula-se a troca constante, o fazer junto e o compartilhamento de saberes criativos: entende-se que pessoas criativas atraem outras pessoas criativas, pois elas se estimulam mutuamente. Como aponta ainda $\operatorname{Klamer}(2016$, p. 8):

\begin{abstract}
Como diversos pesquisadores mostraram, criatividade surge em ambientes criativos. Não importa quão criativos indivíduos possam ser, seus esforços serão inúteis se eles não encontrarem o local certo para crescer. Essa é a razão pela qual economistas adotaram a noção de comunidade criativa. As comunidades se referem a espaços compartilhados que pessoas e organizações têm acesso, uma vez que elas desenvolvem atividades de conexão e associação.
\end{abstract}

A objetivo do projeto aqui proposto é atuar na formação de mulheres em razão de ser este um público mais vulnerável socialmente e, ainda, por serem mulheres a grande maioria das alunas dos cursos oferecidos pela instituição relacionados à produção de vestuário. Como visto pelos dados do Censo de 2010, as mulheres apresentam renda média cerca de $30 \%$ inferior a dos homens na cidade de Belford Roxo. Além da renda mais baixa, aumenta o número de mulheres que chefiam famílias com filhos, segundo dados do IBGE: 


\section{RE ARTE \\ MODA \\ DESIGN}

| http://www.revistas.udesc.br/index.php/Ensinarmode

Figura 6: Gráfico com dados sobre o aumento dos lares chefiados por mulheres.

\section{MULHERES GANHAM ESPAÇO}

Percentual de mulheres e homens chefes de família com filhos na última década

Homens Mulheres

80

60

40

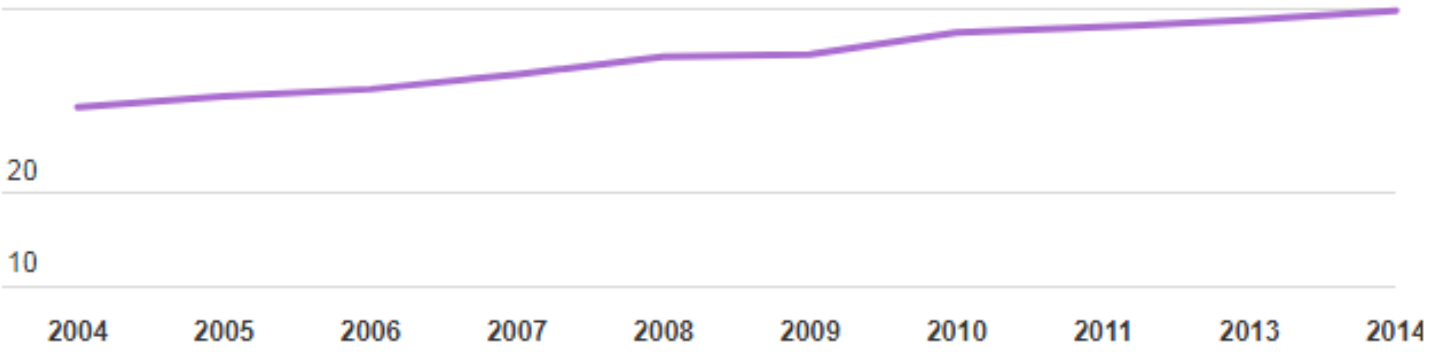

Fonte: Folha de São Paulo a partir de dados do IBGE, 04/12/2015.

É relevante destacar que a área de moda tradicionalmente emprega muitas mulheres, seja na produção - modelagem, costura, etc. -, seja nas áreas de pesquisa e design. Entre as costureiras, profissionais fundamentais para o desenvolvimento das roupas, é comum encontrarmos mulheres com poucos anos de estudo. De acordo com dados apresentados na pesquisa "Territórios da Moda" (2011) desenvolvida pela Prefeitura/RJ em parceria com o Sebrae/RJ, um dos principais problemas do setor, de acordo com os confeccionistas, é a falta de profissionais qualificados, o que acaba por se refletir em baixos salários. Na mesma pesquisa, sabemos que os baixos valores pagos são vistos como o principal problema da profissão, segundo as costureiras. Tal fator revela sua faceta mais crítica e cruel quando sabemos que entre as 5160 costureiras pesquisadas, $51,4 \%$ tem na costura sua única fonte de renda ${ }^{3}$.

Considerando estes dados, é possível afirmar que qualificar estas profissionais ou qualificar futuras profissionais pode ser uma maneira de reduzir os problemas relacionados aos salários. Por esta razão, optou-se em ter como foco do curso a

${ }^{3}$ É interessante ressaltar que a principal vantagem apontada pelas pesquisadas em atuar com costura externa (facção) foi poder cuidar dos filhos, o que revela a importância da moda como profissão para as mulheres. 


\section{RE ARTE \\ MODA \\ DESIGN}

formação de mulheres. Contudo, não basta formar estas profissionais apenas para o exercício da função dentro das confecções, produzindo, assim, mais mão de obra barata para a indústria da moda. Assim, a proposta do curso a ser desenvolvido estaria na qualificação para a autonomia, de maneira que a profissional estivesse capacitada não apenas para receber a produção como faccionista, mas também ser capaz de criar o produto considerando as tendências e o público; comprar a matéria-prima; calcular os custos; precificar sua mão-de-obra e/ou do produto e, mais importante, buscar meios de se associar a outras profissionais em benefício próprio e da coletividade, de modo que a qualificação permitisse o aumento da renda ou mesmo a geração de renda por parte de mulheres dos arredores de Belford Roxo.

A reflexão sobre a proposta é decorrente de diversas discussões entre os docentes em reuniões pedagógicas sobre o contexto social dos alunos que já recebemos e que estão referendados pelos dados acima apresentados sobre o município e sobre a situação da mulher: a grande maioria dos alunos inscritos nos cursos relacionados à produção de vestuário, como já apontado, é mulher e recebeu uma educação básica de baixa qualidade ou já está afastada da escola há muito tempo, estando ou desempregada ou em empregos com altos níveis de precarização. Além da questão da localidade e da situação de gênero, discute-se também continuadamente a baixa autoestima das alunas e a ausência de um projeto de vida e carreira ou mesmo de uma noção mais clara de projeto mais longo para si, no sentido mesmo de uma perspectiva pessoal de crescimento profissional e aumento de renda, incluindo a relação destas questões com saúde e segurança ${ }^{4}$. Neste sentido, o principal diferencial proposto estaria exatamente em oferecer um momento inicial do curso em que se discutisse exatamente estas questões. Embora possa parecer óbvio para os membros das classes medias e altas, a noção de projeto de vida não é natural, mas construída por meio da educação: inicia-se mesmo quando alguém pergunta "o que você quer ser quando

\footnotetext{
${ }^{4}$ Com esta afirmação não indicamos que estas mulheres não projetem suas vidas, mas que este projeto é, em geral, muito imediatista, pouco concreto e/ou envolve pouca crença nas próprias capacidades. Estas características podem ser associadas ao contexto de pobreza que muitas vezes envolve a necessidade de se pensar na concretude imediata da existência, ou seja, nos problemas práticos a serem resolvidos de imediato, como garantir a própria alimentação e a dos filhos aquele dia. Neste sentido, os sonhos e desejos pessoais e de carreira acabam por ter pouca base, pois o presente é muito frágil. De outro lado, todo o contexto educacional reforça a todo o tempo as poucas qualidades e mesmo as dificuldades dos alunos: é comum entre os discentes de baixa renda certa dificuldade em, por exemplo, citar suas qualidades pessoais e profissionais.
} 


\section{RE ARTE \\ MODA \\ DESIGN}

crescer?" Quando não discutida, ela não necessariamente se desenvolverá de uma maneira "natural".

O projeto de vida também envolve nossa constituição como ser, como profissional e mesmo nossa percepção de gênero, raça e até nossa relação com a saúde e segurança: engravidar ou não; proteger-se nas relações sexuais, etc. Esta relação com o projeto impacta em toda a construção do indivíduo como cidadão portador de direitos e mesmo de um indivíduo que prospecta um futuro para si.

Além disso, o curso pretende abordar todas as etapas do processo produtivo dos artigos de vestuário, a fim de fornecer às alunas uma percepção integral do desenvolvimento do produto, de modo a não alienar as mesmas do processo produtivo, compartimentando os conhecimentos: entendemos que, deste modo, contribui-se ainda para a autonomia das alunas como profissionais. Considerando os elementos sociopolíticos e econômicos apresentados acima, a autora traçou os objetivos do curso e os organizou dentro da matriz de articulação abaixo:

Figura 7: Matriz de articulação do curso proposto.

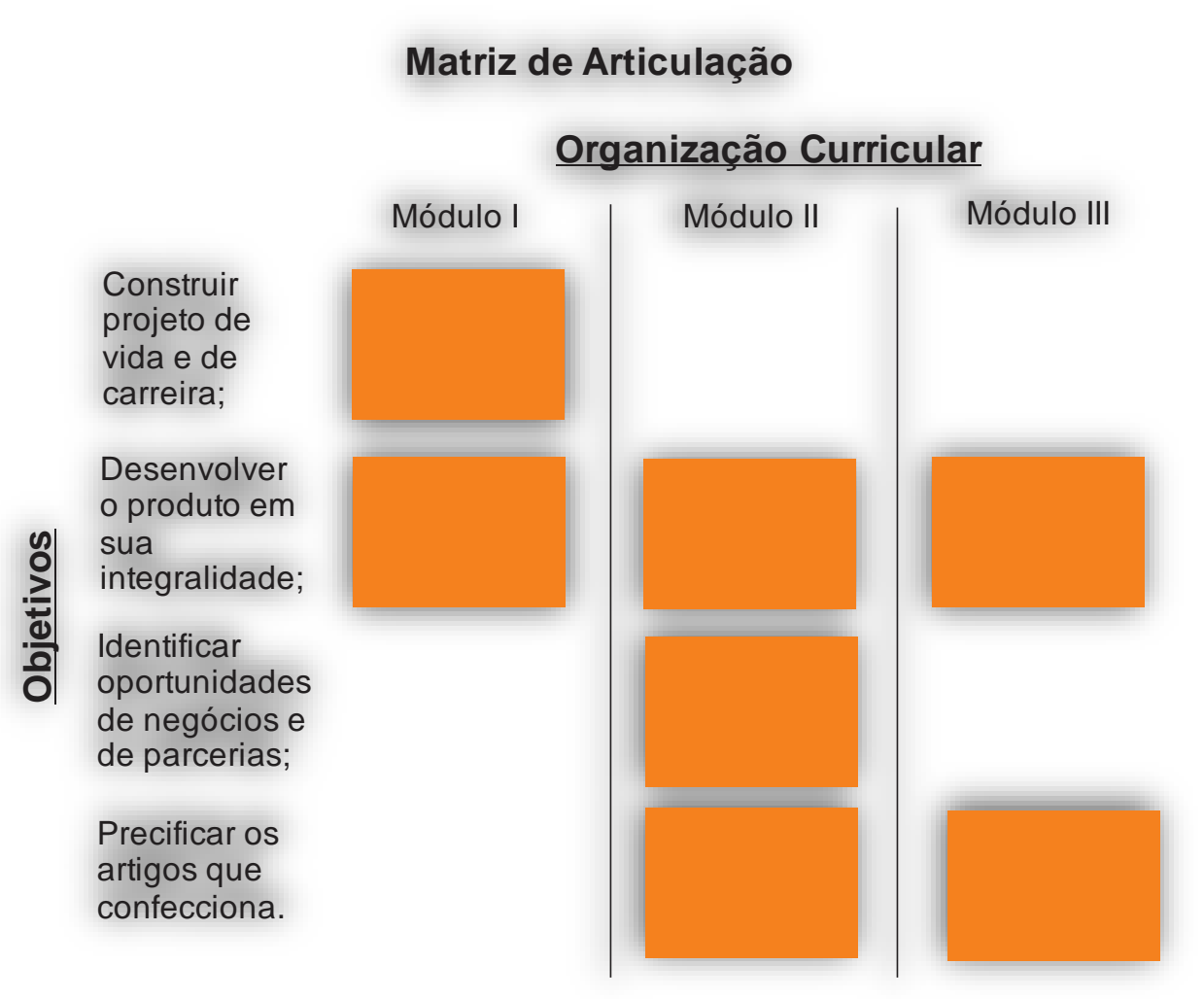

Fonte: Da autora. 


\section{RE ARTE \\ MODA \\ DESIGN \\ | http://www.revistas.udesc.br/index.php/Ensinarmode}

Para o primeiro módulo, selecionou-se os objetivos "Construir projeto de vida e carreira", por meio da disciplina "Projeto de vida e mundo do trabalho" e "Desenvolver o produto em sua integralidade", disciplinas "Matéria-prima I" e "Produto de Moda". As disciplinas de desenvolvimento de produto já parecem desde o primeiro módulo do curso em razão de toda a equipe do campus já ter observado que o adiamento das disciplinas práticas acaba por aumentar a evasão do curso. O tema inclusive já foi pauta em mais de uma reunião da equipe de professores da unidade. Já a disciplina de projeto surge neste momento a fim de atender as questões explicitadas acima sobre o planejamento de vida e carreira.

Para o segundo módulo, além do objetivo "Desenvolver o produto em sua integralidade", que é trabalhada por meio das disciplinas "Matéria-prima II" e "Desenvolvimento de produto I", também é articulado os objetivo "Precificar os artigos que confecciona" nas mesmas disciplinas, pois a discussão sobre a matéria-prima e desenvolvimento de produto passam a abordar questões referentes à negociação de preços e custos/viabilidade dos projetos. Já o objetivo "Identificar oportunidades de negócios e parcerias" é trabalhado na disciplina de "Empreendedorismo para negócios criativos" onde um dos focos centrais e estimular a parceira entre as mulheres que estão no curso.

No último modulo, os objetivos de precificação e de desenvolvimento de produtos são aprofundados por meio de uma abordagem mais acentuada sobre a relação entre custo e preço, enquanto a parte técnica de desenvolvimento de produto é também integralizada. Após o desenvolvimento da matriz, desenvolveu-se o plano de curso: 


\section{RE ARTE MODA DESIGN}

| http://www.revistas.udesc.br/index.php/Ensinarmode

Figura 6: Grade Curricular

curso: Gonfeceionista

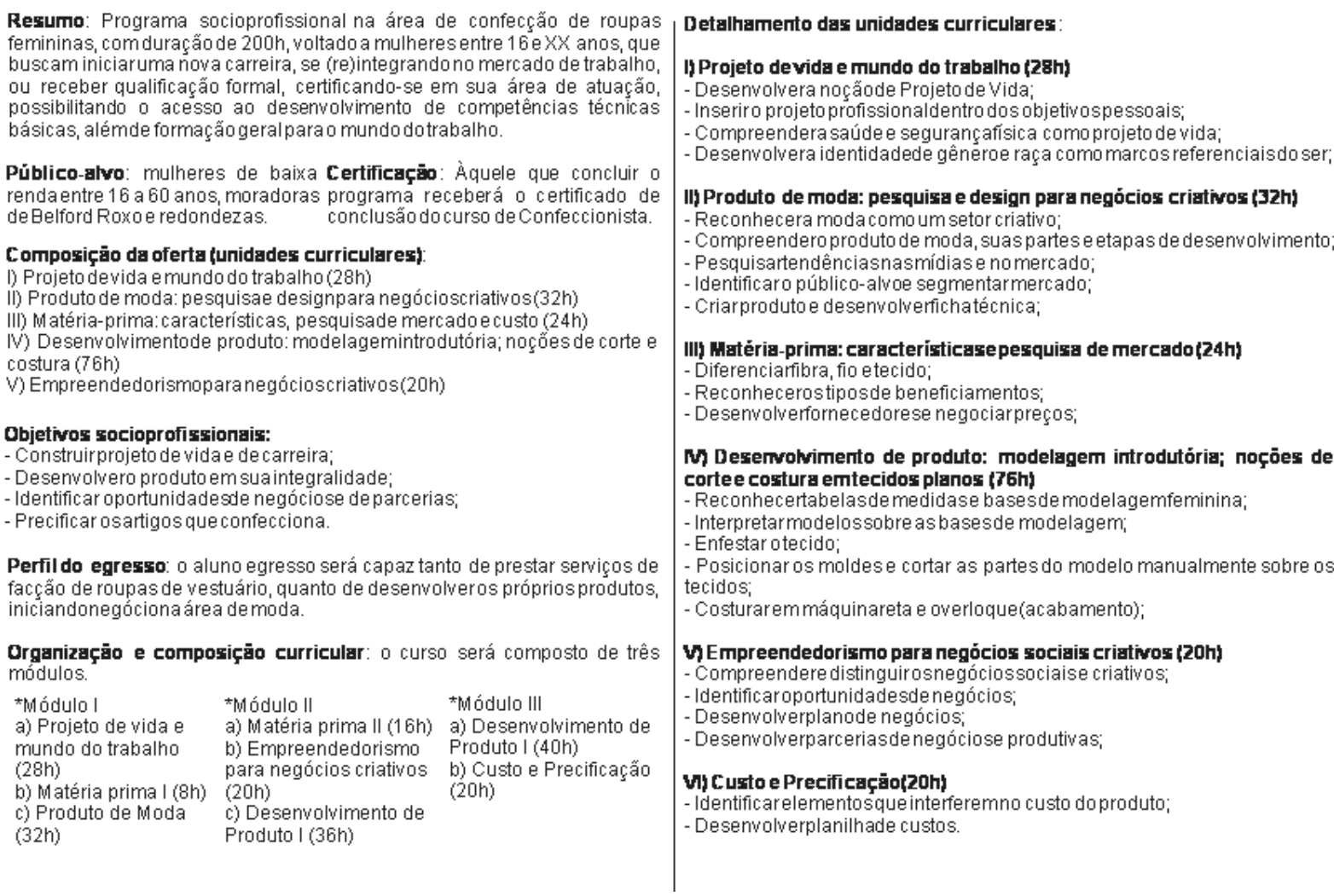

Fonte: IF Belford Roxo.

A discussão e proposição de uma abordagem dos negócios criativos em parceria também é um diferencial: buscaremos desenvolver uma perspectiva centrada na cooperação e não na pura concorrência, objetivando a perspectiva do trabalho em equipe. Busca-se ainda reduzir a própria noção de competição a qual são expostas às mulheres em culturas machistas, como a brasileira.

\section{CONSIDERAÇÕES FINAIS}

Neste artigo, apresentamos o contexto e proposta de atuação da docente como mediador dos processos de geração de renda e redução de desigualdade por meio da discussão de um projeto de curso de moda. Para tal, apresentamos a proposta institucional e as características locais do local onde o mesmo está inserido. Também apresentamos as noções que pautam a economia criativa, conceitos que nortearão o curso. Por fim, apresentamos a estrutura do curso a fim de podermos discuti-lo com os pares. 


\section{RE ARTE \\ MODA \\ DESIGN}

| http://www.revistas.udesc.br/index.php/Ensinarmode

Esta estruturação foi desenvolvida a fim de ser apresentada às equipes dirigentes e pedagógicas a fim de que as mesmas, em conjunto com a docente, possam analisar sua viabilidade e constituição. Assim, é uma proposta a ser analisada por estas equipes. O docente pode ser, assim, um ator fundamental na proposição e desenvolvimento dos cursos, como já indicado na introdução, devendo ser considerado e estimulado na formulação de cursos e materiais pedagógicos da instituição. Por outro lado, as equipes dirigentes e pedagógicas devem, a partir das propostas trazidas pelo docente ou conjuntamente com o mesmo desde o princípio, analisar estes produtos educacionais. Atualmente algumas instituições contam com núcleos docentes estruturantes (NDE) que atuam na reflexão dos cursos, mas infelizmente muitos entre eles não são estimulados a se reunir de fato ou são fornecidas a este núcleo, um lugar de segunda categoria.

Grupos de trabalhos docentes para o planejamento de cursos e materiais devem ser estimulados nas instituições com a possibilidade de estas atividades serem consideradas como carga horária, ou seja, que esta atividade não seja inserida como mais uma atividade a ser inserida como atividade de planejamento, sobrecarregando o professor nas horas de planejamento de aula, correção e lançamento de graus e frequências nos sistemas. A instituição deve mesmo remunerar os docentes para estas atividades, estimulando, assim, a pesquisa e extensão na área pedagógica e de desenvolvimento de materiais didático-pedagógicos e cursos para a mesma. As instituições públicas, por sua vez, devem ainda acentuar o caráter sociopolítico fundamental das propostas de curso e materiais, considerando o papel social destas últimas.

No que se refere em específico às áreas criativas, há de se discutir a formação docente para estas áreas. Não há licenciatura específica para muitas áreas, o que se relaciona a questões particulares da legislação educacional brasileira, mas deve-se discutir como capacitar profissionais provenientes do mercado e que não possuem prática didático-pedagógica ou que muitas vezes acabaram de se formar e encontram na docência uma possibilidade profissional. O conhecimento técnico-prático e a experiência profissional são de central importância para os professores das áreas criativas, mas não se pode dispensar a formação didático-pedagógica. Este, contudo, é um tema instigante e que demanda pesquisa, de modo que deixaremos para discutí-lo futuramente em outros artigos. 


\section{RE ARTE \\ MODA \\ DESIGN}

\section{REFERÊNCIAS}

CANO, Ignácio; SENTO-SÉ, João Trajano; RIBEIRO, Eduardo. Mapeamento da criminalidade na área metropolitana do Rio de Janeiro. 2004. Disponível em: $<$ http://www.lav.ueri.br/docs/rel/2004/map crim rio 2004.pdf >. Acesso em: 09 Jul. 2017;

DE MARCHI, Leonardo. "Entre o desenvolvimento econômico e o direito à cultura: uma análise dos usos do termo 'economia criativa' pelo governo brasileiro". In. Anais do XI Congreso Latinoamericano de investigadores de la comunicación. 2012a.

Disponível

em: $<$ http://alaic2012.comunicacion.edu.uy/sites/default/files/leonardo de marchi econo mia criativa e politicas de cultura artigo 1.pdf $>$. Acesso em: 10/07/2014.

"Construindo o conceito de economia criativa no Brasil: política cultural no contexto neodesenvolvimentista brasileiro". In. Anais do XXXV Congresso Brasileiro de Ciência da Comunicação/INTERCOM. 2012b. Disponível em: <www.intercom.org.br/sis/2012/resumos/R7-2053-1.pdf>. Acesso em: 10/07/2014.

- Construindo um conceito neodesenvolvimentista de economia criativa no Brasil: Política Cultural na era do novo MinC. Novos Olhares, São Paulo, v. 2, n. 2, jul./dez. 2013. Disponível em: $<$ www.revistas.usp.br/novosolhares/article/viewFile/69826/72486>. Acesso em: $10 / 07 / 2014$

FIRJAN. A Cadeia da Indústria Criativa no Brasil. In. Estudos para o desenvolvimento do Estado do Rio de Janeiro, n.2, mai. 2008. Disponível em: $<$ http://www.firjan.org.br/data/pages/2C908CEC3286DF68013286FCB8CE2E1C.htm $\geq$. Acesso em: 23/07/2014.

IBGE. Cidades: Belford Roxo. 2016. Disponível em: $<$ http://www.cidades.ibge.gov.br/xtras/perfil.php?lang=\&codmun=330045\&search=||infogr \%E1ficos:-informa\%E7\%F5es-completas $>$. Acesso em: 08 Jul. 2017;

MICHETTI, Micheli. "Da mestiçagem como panaceia à diversidade como (anti) commodity: notas sobre economia criativa no Brasil". In. Latitude, v. 6, n. 2, pp. 175190, 2012b. Disponível em: $<$ http://www.seer.ufal.br/index.php/latitude/article/view/877/573>. Acesso em: $11 / 07 / 2014$.

MINC. Plano da Secretaria de Economia Criativa: Políticas, diretrizes e ações 2011-2014. Brasília: MINC, 2012;

PACHECO, Eliezer. Os institutos federais: uma revolução na educação profissional e tecnológica. Brasília: MEC, s/a; 


\section{RE ARTE \\ MODA \\ DESIGN \\ | http://www.revistas.udesc.br/index.php/Ensinarmode}

PNUD. Ranking IDHM Municípios 2010. 2013. Disponível em: $<$ http://www.br.undp.org/content/brazi//pt/home/idh0/rankings/idhm-municipios-

2010.html . Acesso em: 08 Jul. 2017;

PREFEITURA/RJ; SEBRAE/RJ. Territórios da moda: a indústria da moda na cidade do Rio de Janeiro [Relatório de Pesquisa: Etapa Quantitativa]. Rio de Janeiro: Prefeitura/RJ, 2011;

REIS, Ana Carla Fonseca (Org). Economia Criativa como estratégia de desenvolvimento: uma visão dos países em desenvolvimento. São Paulo: Itaú Cultural, 2008;

SILVA, Caetana Juracy Resende. Institutos Federais Lei 11.892, de 29/12/2008: comentários e reflexões. Natal: IFRN, 2009;

SOROSINI, Marcela. Polos de Jeans no Rio vendem calça a $\mathrm{R} \$ 20$. 0 dia [Caderno Economia]. 17/09/2015. Disponivel em: $<$ https://extra.globo.com/noticias/economia/polos-de-jeans-no-rio-vendem-calcas-partirde-20-8287085.html >. Acesso em 08 Jul. 2017;

KLAMER, Arjo. Pensar Economia Criativa pede por outra ciência econômica: introduzindo a abordagem "Value Based". In.: VALIATI, Leandro; MOLLER, Gustavo. (Org.). Economia criativa, cultura e políticas públicas. Porto Alegre: Editora da UFRGS/CEGOV, 2016.

UNCTAD/Conferência das Nações Unidas para Comércio e Desenvolvimento. Relatório de economia criativa 2010. Nações Unidas, 2010;

WIKIPEDIA. Baixada Fluminense. 21/5/2017. Disponível em: $<$ https://pt.wikipedia.org/wiki/Baixada Fluminense $>$. Acesso em: 09 Jul. 2017; 